\title{
La cultura digital en la enseñanza y el aprendizaje de la historia de nivel medio
}

Digital culture in the teaching and learning of History in High Schools

Víctor Salto*

Graciela Funes**

\section{RESUMEN}

En los artículos que anteceden, se presentaron datos y argumentos en relación a la cultura digital en la enseñanza y el aprendizaje de la historia. En esta oportunidad nos interesa dar a conocer qué enseñanzas y aprendizajes circulan en esa línea en escuelas de nivel medio de la Nord Patagonia Argentina. Y en particular, compartir dos casos de construcción colaborativa de propuestas de enseñanza con profesores en historia y los alcances identificados en el aprendizaje de sus estudiantes.

Palabras claves: cultura digital; enseñanza y aprendizaje de la Historia; profesorado; estudio de casos.
Abstract

In the previous articles, data and arguments were presented in relation to digital culture in History teaching and learning. In this text we aim to publicize teaching and learning experiences in High Schools of the Nord Patagonia Argentina, and, especially, share two cases of collaborative construction of teaching proposals in History and the results identified in student learning.

Keywords: digital culture; teaching and learning History; faculty; case studies.

Como ya anticipamos, la investigación en el nivel medio fue iniciada con un cuestionario que nos permitió realizar un primer sondeo sobre la temática. El cuestionario se implementó en 19 escuelas ubicadas entre las provincias de Rio Negro y Neuquén. ${ }^{1}$ Luego de ello avanzamos, en un segundo sondeo, a partir de la realización de entrevistas en profundidad a profesores/as de histo-

\footnotetext{
* Especialista en Didáctica de las Ciencias Sociales. Área: Didáctica. Facultad de Ciencias de la Educación. Universidad Nacional del Comahue. Neuquén, Argentina. victorsalto26@gmail.com

** Doctora en Educación. Área: Didáctica. Facultad de Ciencias de la Educación. Universidad Nacional del Comahue. Neuquén, Argentina. agfunes@hotmail.com
} 
ria de algunas de esas escuelas. Entrevistas que se llevaron a cabo teniendo en cuenta la existencia de indicios de experiencias de enseñanza de la historia en relación con la cultura digital, la existencia de infraestructura tecnológica en los establecimientos en los que trabajan, y de su predisposición para con nuestra investigación. El propósito de las entrevistas en profundidad residió en focalizar en las experiencias concretas que nos permitieran delimitar nuestro estudio de casos.

A partir de la realización de las mismas pudimos abordar aspectos vinculados a: ¿qué prácticas mediadas por lo digital reconoce el profesorado en la enseñanza de la historia de nivel medio? ¿Qué presencia y alcance tienen los dispositivos tecnológicos en las clases de historia? ¿Para qué los usan profesores/as en historia? ¿Qué límites y posibilidades reconocen éstos/as en su utilización y en la construcción de materiales y recursos de enseñanza?² Las respuestas obtenidas sirvieron de plataforma para comenzar a definir acuerdos y criterios a convenir con los casos seleccionados. Lo cual nos permitió avanzar en la preparación de propuestas de enseñanza que incorporaran dispositivos didácticos digitales a partir de los cuales enseñar y que se aprenda historia. Y posteriormente evaluar de manera conjunta con el estudiantado sus límites, alcances y aspectos a revisar en relación a un aprendizaje escolar orientado a la formación del pensamiento y de la conciencia histórica.

\section{De la Delimitación De los Casos a LA CONSTRUCCIÓN DE DISPOSITIVOS DIGITALES}

En la etapa de búsqueda de una lectura cultural de lo que acontece con la tecnología y la digitalización en la enseñanza y el aprendizaje de la historia, se trabajó con dos profesores de nivel medio. Esta instancia se abordó a partir del intercambio de ideas, experiencias, materiales, y el planteo de los alcances previstos en nuestro proyecto de investigación. De esta manera, los profesores de historia pusieron a disposición los cursos que tenían a cargo y tuvieron una activa participación en el marco de la investigación emprendida. No solo por la valoración positiva que en sus prácticas docentes venían realizando sobre la incorporación de lo digital, sino también porque - a partir de 
criterios compartidos - reformularon activamente la organización de sus propuestas de enseñanza. En este sentido, desde nuestro trabajo como investigadores ofrecimos orientaciones sobre criterios didácticos que permitieran plasmar ambas experiencias en formas y tiempos acotados y realizables. El profesorado participante ofreció los cursos a cargo para nuestra participación en los mismos, definió los temas sobre los cuales enseñar incorporando lo digital en cada caso, y conjuntamente clarificamos la intencionalidad por la cual orientar cada propuesta. A partir de ello, y de manera colectiva entre profesores e investigadores, elaboramos ambas propuestas e iniciamos su desarrollo en cada curso de manera co-participativa y conjunta. Cada clase fue entonces desarrollada, a partir de lo secuenciado, con la intervención de profesores a cargo y nuestra participación como investigadores participantes en todos los encuentros.

Ambos profesores, contaban con experiencias distintas en la docencia. Se ubicaban dentro de una franja que abarca de los 4 a los 10 años de antigüedad, y mantenían al menos 4 años de estabilidad laboral en establecimientos educativos de la ciudad de Neuquén y en escuelas consideradas de primera categoría. ${ }^{3}$ También contaban con cierta experiencia acumulada en el manejo de dispositivos digitales para la enseñanza de la historia. Aunque en este aspecto esas experiencias las hayan movilizado solo de manera autodidacta y sin perspectivas teóricas de referencia.

La selección de ambos casos se fue delimitando entonces a partir de estos indicadores y de los datos que nos ofrecieron las entrevistas en profundidad. Información a partir de la cual fuimos estableciendo los acuerdos mínimos que nos permitieran emprender el trabajo cooperativo que nos planteábamos.

Un primer acuerdo con los profesores implicados en el que se sostuvo el trabajo emprendido consistió en reconocer la existencia de la influencia de lo digital en la cultura juvenil y observar la alteración que realiza en la mediación escolar (Dussel, 2010). Los lenguajes mediados por la cultura digital aparecieron entonces como un espacio destacado para poder referirse a sucesos y procesos históricos cuyas consecuencias parecen proyectarse permanentemente sobre nuestra vida contemporánea. El cine, la televisión e internet fueron considerados mediadores importantes en la reconstrucción del pasado y en los 
modos en los que se puede conocer y reconstruir el pasado, sea lejano/cercano a las experiencias de los/las estudiantes.

No obstante, también se reconoció que la incorporación de esas mediaciones digitales no siempre es fácil de recuperar en el desarrollo de sus clases y que no puede generalizarse como una iniciativa del conjunto del profesorado. Aspecto que continúa actuando como condicionante en tanto expresa la existencia de dificultades significativas para una incorporación plena de dispositivos tecnológicos en las clases de historia.

En relación a esas dificultades, otro punto de acuerdo se identificó en la cuestión del abismo generacional entre el profesorado y el estudiantado respecto al uso de la tecnología. Aspecto relevante que, sin embargo, se consideró puede tratarse como un abismo que excede a los condicionantes materiales y al "temor" a no saber utilizar las tecnologías (lo cual juega un rol importante dentro de las representaciones del profesorado). Y que abarca también el problema de no contar con una preparación adecuada para su incorporación; vinculándose con las limitaciones propias de la formación docente continua.

En este sentido, un tercer punto de acuerdo residió en la necesidad de plantear la posibilidad de tender a superar algunas tradiciones reconocidas por el profesorado sobre sus prácticas de enseñanza. En particular, las vinculadas al predominio de la cultura impresa y escrita generando otras instancias de comunicación, relación y construcción colectiva de conocimientos históricos escolares con el estudiantado en sus clases. Y junto a ello, generar otras percepciones sobre la utilidad social de la historia, favoreciendo otros modos de comprensión histórica, y de cambiar las formas de enseñar historia a partir de otros recursos. En esta dirección, pudimos articular la iniciativa de los casos seleccionados con el propósito de favorecer situaciones de enseñanza y aprendizaje a partir de la incorporación de lo digital para contribuir a la formación de un pensamiento y conciencia histórica. Perspectiva que ofrecimos para orientar ambas experiencias. ${ }^{4}$

Estas orientaciones, nos permitieron partir del presupuesto de que no siempre el uso y buen manejo de las tecnologías es una garantía para su incorporación y mediación adecuada en la enseñanza de la historia. Y que este 
supuesto también implica al estudiantado de nivel medio y al uso que hace de lo digital en las clases de historia. Ellos/as pueden sobrepasarnos en su uso, tener más facilidades en su manipulación técnica, pero ese uso no siempre lo realizan con fines educativos. O bien, no siempre lo hacen en relación a contenidos históricos específicos. Aspecto que consideramos importante por dos cuestiones en particular. Por un lado, porque el reconocido abismo generacional entre profesores y estudiantes no es indicativo de ventajas en relación "a..." saber en mejores condiciones sobre la historia que se enseña y que se aprende (Salto, 2015). Por otro, porque la brecha creciente pareciera estar entre lo que hacen los jóvenes dentro de las clases de historia y lo que hacen fuera de ellas en relación al uso de su cultura y de los dispositivos digitales. Fuera de ella, los/ las jóvenes parecen vivir en una cultura mediática sin precedentes. Cultura a la que no apelan dentro de la escuela, y que muy pocos de ellos/as la orientan hacia un uso de la tecnología en relación al aprendizaje escolar de la historia. Esto es, lo que Buckingham denomina como una especie de disyunción entre la cultura escolar y la cultura cotidiana de los/las jóvenes, como una "nueva brecha digital" (Buckingham, 2008).

Superar esa brecha se presentó entonces como un desafío sobre el cual avanzar para favorecer - a partir de otras mediaciones posibles - la formación del pensamiento y conciencia histórica. Entendiendo que era necesario educar para los medios superando la idea del uso de los dispositivos como simples medios neutrales de distribución de información. Es decir, ir más allá del uso instrumental de la tecnología, considerándolos como formas de cultura y de comunicación con un enorme potencial para el aprendizaje de la historia. Lo cual implica trabajar incluso sobre la resistencia que - dentro del propio estudiantado de nivel medio - observan profesores/as al momento de pensar en su incorporación. Y la exigencia de incorporar otra lógica de construcción de conocimientos históricos en las clases de historia.

En esta línea, se consideró finalmente que la incorporación de dispositivos digitales puede permitir beneficios educativos. Pero que éstos se diluyen si esa incorporación se mantiene solo para la administración de rutinas escolares y la preparación de materiales de enseñanza y no para lograr una integración más plena en su enseñanza. Si existe mediación de lo digital en sus prácticas 
de enseñanza y en la forma en que aprenden historia sus estudiantes (Salto, 2015), partimos de considerar que sus límites y posibilidades son relativos. Y que su alcance depende de criterios mínimos a partir de los cuales organizar propuestas de enseñanza que promuevan aprendizajes de la historia que permitan una integración más plena de esos dispositivos.

En este aspecto, se trabajó entonces sobre tres criterios para la organización y construcción de esos dispositivos. Estos fueron:

- Delimitar el tema: ¿Qué enseñar?;

- Establecer las finalidades: ¿Para qué quiero enseñarlo?

- Organizar secuencias didácticas en momentos de trabajo por clase y de manera colaborativa: ¿A partir de que recursos enseñar y cómo hacerlo?

Con ambos profesores, estos criterios nos permitieron organizar cada secuencia didáctica e ir avanzando en la construcción del dispositivo antes y durante el propio desarrollo de cada caso. Y luego, realizar balances entre pares y con los propios/as estudiantes con los/las cuales se llevaron a cabo ambas experiencias.

En esta dirección, se consideró importante trabajar cuestionando el determinismo tecnológico que caracteriza el debate respecto de la inclusión (o no) de tecnologías digitales en el aula y evaluar el impacto que puede tener su incorporación en el aprendizaje de la historia. Midiendo sus potencialidades pero también esperando sus consecuencias no deseadas. Es decir, ir a la práctica de enseñanza de manera organizada pero en búsqueda de sus alcances en el aprendizaje de la historia de jóvenes de nivel medio.

Finalmente, es importante destacar que estos acuerdos y aspiraciones se enmarcaron en la búsqueda de nuevos horizontes en los que la enseñanza de la historia debe pensarse. Horizontes permeados por prácticas de enseñanza de la historia que, según se consideró, se encuentran atravesadas por una diversidad de situaciones mediadas por lo digital y situaciones didácticas heterogéneas, que en términos generales se caracterizaron como:

- prácticas en la que se da y se pueden ofrecer una diversidad de relaciones con el conocimiento histórico; 
- prácticas en las que se altera y se pueden reconfigurar las formas de enseñar y aprender historia; $y$

- prácticas donde las tecnologías se usan, pero sin garantía de articular plenamente lo digital con la enseñanza de la disciplina.

A partir de algunas de estas claves, avanzamos en el trabajo colaborativo con dos casos en particular sobre enseñanza y aprendizaje de la historia en la cultura digital. Casos que nos hicieron partícipes de situaciones en las que la digitalización de la cultura demandó de nuevas alfabetizaciones escolares.

\section{DE LA ENSEÑANZA DE LA HiSTORIA EN LA CUlTURA DIGITAL...}

A partir de esos presupuestos y acuerdos iniciales, organizamos el trabajo con cada profesor en dos grandes momentos. Un primer momento de trabajo orientativo, colectivo y de conjunto sobre la construcción de las propuestas para la enseñanza de la historia donde se incorpore lo digital. Y un segundo momento de desarrollo e implementación de dichas propuestas y de su enseñanza en base a criterios de secuenciación mínimos.

En ambos momentos, pensamos y accionamos con el profesorado propuestas que ubiquen a los/las estudiantes en un rol más activo en los procesos de aprendizaje de la historia y ofrezcan oportunidades de un uso creativo de las tecnologías. Por un lado, brindando herramientas que no podrían utilizar en otros ámbitos de mediación digital. Por otro lado, generando y permitiendo un espacio de reflexión sobre su potencial en relación al aprendizaje de la historia.

En este sentido, la organización de ambas propuestas (Ver Cuadro 1) y su posterior desarrollo en las clases de historia se realizaron en paralelo. Se trabajó en dos establecimientos escolares distintos. La propuesta 1 fue implementada con un primer año, división B, de historia del C.P.E.M. $\mathrm{n}^{\circ} 41$ (con orientación en humanidades) y la propuesta 2 en un primer año, división B, de historia del colegio Don Bosco. ${ }^{5}$ 


\section{Cuadro 1}

Propuesta 1

Propuesta 2

\begin{tabular}{|c|c|c|}
\hline Escuela: & Centro Provincial de Enseñanza Media ${ }^{\circ} 41$ & Colegio Don Bosco \\
\hline Asignatura: & Historia & Historia \\
\hline Curso y Turno: & $1^{\circ} \mathrm{B} / \mathrm{Mañana}$ & $1^{\circ} \mathrm{B} / \mathrm{Mañana}$ \\
\hline Localidad: & Neuquén Capital & Neuquén Capital \\
\hline $\begin{array}{l}\text { 1. Tema: } \\
\text { ¿Qué enseño? }\end{array}$ & $\begin{array}{l}\text { EGIPTO: el Estado prístino organizado como Estado } \\
\text { teocrático. ¿Quiénes y cómo gobiernan en Egipto } \\
\text { antiguo? }\end{array}$ & $\begin{array}{l}\text { La conquista de América: } \\
\text { El choque cultural. }\end{array}$ \\
\hline $\begin{array}{l}\text { 2. Finalidades: } \\
\text { ¿Para qué quiero } \\
\text { enseñarlo? }\end{array}$ & $\begin{array}{l}\text { Promover la reflexión y reconocimiento de las formas } \\
\text { a partir de las cuales un Estado teocrático organiza e } \\
\text { impone su poder en la vida cotidiana de sus } \\
\text { habitantes. Visibilizando en particular: ¿Cómo vivían } \\
\text { en el antiguo Egipto? ¿Cómo era la vida en sus } \\
\text { ciudades? y ¿cómo se expresaba la imposición de ese } \\
\text { poder en el arte? }\end{array}$ & $\begin{array}{l}\text { Poner en discusión el } \\
\text { impacto de la conquista } \\
\text { española sobre la } \\
\text { organización de los } \\
\text { pueblos indígenas a } \\
\text { partir de la reflexión y } \\
\text { debate sobre la palabra } \\
\text { de los "vencidos". }\end{array}$ \\
\hline
\end{tabular}

\section{Organización de la secuencia en momentos de trabajo por clase:}

\section{CLASE 1}

$1^{\circ}$ momento
Retomar los conceptos de Estado Prístino (de M.

Harris) y Estado Teocrático y realizar una caracterización de los principales factores sobre los cuales se organizó ese Estado. (Presentación breve de red conceptual acompañada de mapas e imágenes fotográficas).
Retomar las ideas trabajadas sobre las causas del dominio español y realizar una contextualización histórica de la conquista de España sobre América y el choque cultural que involucró (presentación breve o red conceptual acompañada de mapas). Analizar imágenes sobre el encuentro de la otredad. Escribir las reflexiones en el pizarrón. 


\begin{tabular}{|c|c|c|}
\hline $2^{\circ}$ momento: & $\begin{array}{l}\text { Visualización de video: La Eduteca - Momentos de la } \\
\text { Historia - La Edad Antigua: Egipto: } \\
\text { https://www.youtube.com/watch?v=qtO3_7cWSKk } \\
\text { (duración: } 6 \text { minutos y } 24 \text { segundos). }\end{array}$ & $\begin{array}{l}\text { Presentar y escuchar un } \\
\text { cuento en formato video } \\
\text { a partir del cual } \\
\text { identificar en qué } \\
\text { impactó ese choque } \\
\text { cultural sobre los pueblos } \\
\text { originarios. Relato de } \\
\text { Eduardo Galeano: "El } \\
\text { descubrimiento" } \\
\text { (cuento): } \\
\text { https://www.youtube. } \\
\text { com/ } \\
\text { watch?v=sdPlDnaL2_4 } \\
\text { (duración: } 1 \text { minuto y } 20 \\
\text { segundos) } \\
\text { Preguntas para la } \\
\text { reflexión: } \\
\text { ¿Cómo describe el } \\
\text { "encuentro con el otro"? } \\
\text { ¿Qué descubrieron el } 12 \\
\text { de Octubre los pueblos } \\
\text { indígenas? } \\
\text { ¿Quiénes piensan esto? } \\
\text { ¿Por qué? }\end{array}$ \\
\hline $3^{\circ}$ momento: & $\begin{array}{l}\text { Realización de manera colectiva de un texto } \\
\text { explicativo en clase en base a lo visto en el video } \\
\text { anterior. Escribir en hoja de Word dicho texto } \\
\text { (visibilizado por todos/as en la pantalla del proyector) } \\
\text { y armar redes conceptuales explicativas con los/las } \\
\text { estudiantes (mostrando el uso de las herramientas de } \\
\text { Word para armar celdas y conectores conceptuales en } \\
\text { el desarrollo mismo del texto). } \\
\text { Pregunta a responder colectivamente en el texto } \\
\text { explicativo: } \\
\text { ¿Cuáles son las principales características que } \\
\text { presenta el Estado Teocrático en Egipto antiguo? }\end{array}$ & $\begin{array}{l}\text { Reflexión y escritura de } \\
\text { las ideas principales } \\
\text { registradas en las } \\
\text { respuestas de los/las } \\
\text { estudiantes: ¿Quién } \\
\text { descubrió a quién? } \\
\text { ¿Hubo descubrimiento? }\end{array}$ \\
\hline \multicolumn{3}{|c|}{ CLASE 2} \\
\hline $1^{\circ}$ momento & $\begin{array}{l}\text { Iniciar con preguntas sobre conceptos y sus relaciones } \\
\text { con las características del Estado antiguo en Egipto - } \\
\text { trabajadas en el encuentro anterior. }\end{array}$ & $\begin{array}{l}\text { Reflexionar en torno a: } \\
\text { ¿Qué es conquistar? } \\
\text { ¿Cómo se dio la conquista } \\
\text { en américa? ¿Hubo } \\
\text { choque cultural a partir de } \\
\text { este proceso? ¿Por qué? }\end{array}$ \\
\hline
\end{tabular}




\begin{tabular}{|c|c|c|}
\hline $2^{\circ}$ momento & $\begin{array}{l}\text { Visualizar en pantalla de proyector un ejemplo de } \\
\text { presentación en PowerPoint de un subtema sobre } \\
\text { Egipto antiguo: ¿Cuáles son las características de } \\
\text { su territorio? Realización simultánea de } \\
\text { sugerencias sobre el formato a organizar para la } \\
\text { presentación incluyendo: ¿Cómo presentar una } \\
\text { imagen? ¿Cómo incrustar un efecto? ¿Qué mirar } \\
\text { de una imagen fotográfica en relación a un } \\
\text { subtema sugerido? }\end{array}$ & $\begin{array}{l}\text { Visualización del cuento } \\
\text { "los sueños del viejo } \\
\text { Antonio" en formato } \\
\text { audiocuento: } \\
\text { https://www.youtube. } \\
\text { com/watch?v=- } \\
\text { v32sKgQIJo (duración: } 2 \\
\text { minutos y } 32 \text { segundos) } \\
\text { Preguntas para la } \\
\text { reflexión: } \\
\text { ¿Qué sueña el viejo } \\
\text { Antonio? } \\
\text { ¿Qué relación encuentran } \\
\text { con el cuento de la clase } \\
\text { anterior? }\end{array}$ \\
\hline $3^{\circ}$ momento & $\begin{array}{l}\text { Planteo de la actividad de realización de presentación } \\
\text { PowerPoint en relación a la elección de uno de los } \\
\text { siguientes subtemas: } \\
>\text { ¿Cómo vivían en el antiguo Egipto? } \\
>\text { ¿Cómo era la vida en sus ciudades? } \\
\text { ¿Cómo se expresaba la imposición de ese poder } \\
\text { en el arte? }\end{array}$ & $\begin{array}{l}\text { Organización y } \\
\text { sugerencias para la } \\
\text { elaboración de un } \\
\text { audiocuento en formato } \\
\text { PowerPoint. Presentación } \\
\text { en base a: } \\
\text { Las distintas miradas } \\
\text { sobre el proceso. } \\
\text { Imágenes que den cuenta } \\
\text { de esa mirada. } \\
\text { Un relato escrito narrado. }\end{array}$ \\
\hline \multicolumn{3}{|c|}{ CLASE 3} \\
\hline $1^{\circ}$ momento: & $\begin{array}{l}\text { Presentación en PowerPoint de los subtemas } \\
\text { seleccionados por grupo en base a: } \\
\text { Un desarrollo explicativo del PowerPoint sobre el } \\
\text { subtema seleccionado; } \\
\text { Una explicación de las imágenes seleccionadas; } \\
\text { Una justificación de la selección del subtema; } \\
\text { Una argumentación sobre ¿por qué el subtema } \\
\text { seleccionado permite demostrar el modo en que el } \\
\text { Estado teocrático organiza e impone su poder en la } \\
\text { vida cotidiana? }\end{array}$ & $\begin{array}{l}\text { Presentación de los } \\
\text { audiocuentos en } \\
\text { formato PowerPoint. }\end{array}$ \\
\hline
\end{tabular}




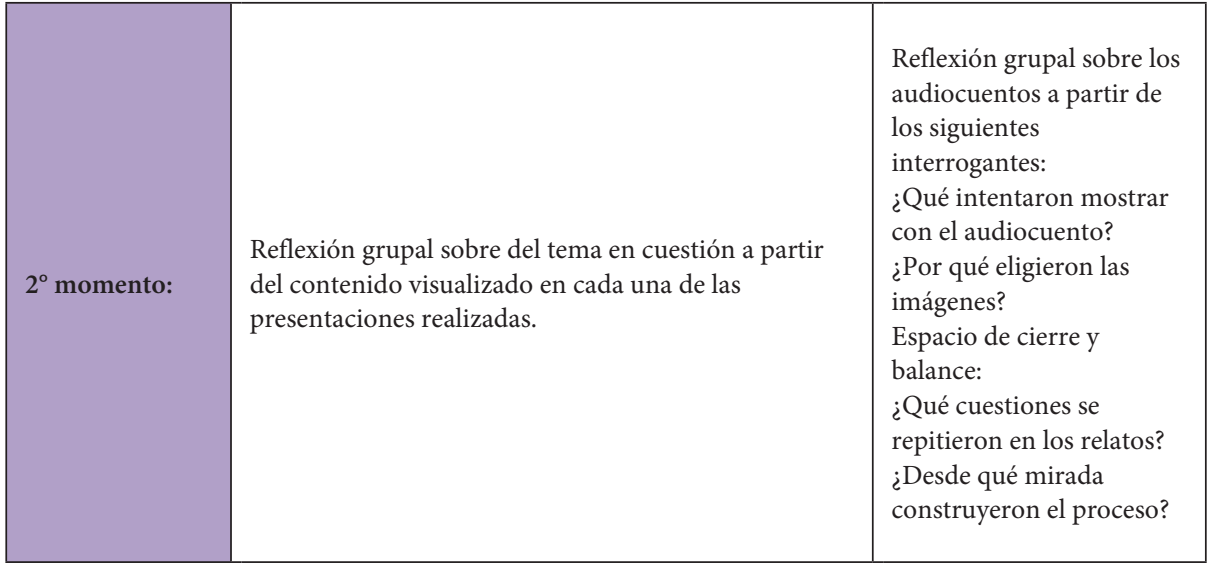

Fuente: elaboración propia.

En el caso de la propuesta 1, el tema enseñado fue Egipto en la antigüedad a partir de la problematización sobre la organización del poder impuesta por el Estado teocrático y su expresión en la vida cotidiana de sus habitantes. Se desarrolló en tres clases a través de las cuales los contenidos fueron trabajados recurriendo principalmente a un dispositivo digital: el PPT (PowerPoint).

En la primera clase, se trabajó inicialmente a partir de la presentación de un PowerPoint sobre las principales características del Estado teocrático y la forma en que se organizó el ejercicio del poder sobre la sociedad antigua. El Power presentaba conceptos y características relacionadas a:

- ¿Qué es y por qué es teocrático?

- ¿Qué es y por qué es politeísta?

- ¿Por qué se caracteriza por desarrollar una gran riqueza económica?

- ¿Por qué necesita de un gran número de funcionarios para imponerse?

La presentación se acompañó de mapas que permitieran ubicar geográficamente el domino territorial del Estado teocrático. Luego de la misma se proyectó un video de corta duración a partir del cual se pudieron visualizar imágenes de referencia y explicaciones sobre los subtemas que se iban a sugerir posteriormente para armar una presentación propia y en grupo por parte de los/las estudiantes. A partir del video visto, se abrió una hoja de Word para que los/las estudiantes siguieran la elaboración -a partir de sus aportes sobre 
lo visto en el video- de un escrito y pudieran copiar y escribir en sus carpetas, en sus computadoras, y en algunos casos en sus propios celulares. El desarrollo del texto que se escribió consistió en construir una respuesta colectiva a la pregunta: ¿Cuáles son las principales características que presenta el Estado Teocrático en Egipto antiguo? Respuesta elaborada a partir de la presentación del PowerPoint inicial y el video observado.

En la segunda clase de la propuesta 1, se recuperó lo realizado en el primer encuentro y se avanzó en la organización de la presentación del contenido a exponer. En este sentido, el segundo encuentro fue más de carácter organizativo y residió en prestar mayor atención a resolver sobre el cómo armar dicha presentación. Ante esto desarrollamos un ejemplo retomando las características territoriales sobre las cuales se desplego el poder de los faraones egipcios. Se presentó para ello un Power con imágenes específicas y explicaciones textuales concisas sobre las condiciones físicas y la identificación de las principales ciudades del territorio en cuestión. En este aspecto, el trabajo demando un detenimiento mayor del esperado en la medida en que se tuvieron que abordar cuestiones vinculadas al uso del programa de manera simultánea con el planteo de la especificidad del contenido. Luego de ello, se presentaron los subtemas sugeridos y la organización de los grupos para la exposición de sus presentaciones.

Finalmente, en la última y tercera clase, comenzamos con las presentaciones de los Power realizados por grupo. Esto demando a los/las estudiantes la realización previa de una presentación en PowerPoint en la que debieron mostrar información (datos que consideraron importantes) e imágenes que ilustren lo que querían mostrar sobre el subtema. Realizaron un total de siete presentaciones, cada una sobre un subtema en particular de los sugeridos. En cinco casos, el subtema seleccionado se reiteró (“¿Cómo vivían en el antiguo Egipto?”) pero las elaboraciones realizadas se distinguieron por el modo de presentación, las imágenes seleccionadas y el texto escrito con el que acompañaron las imágenes presentadas. Mientras que en dos presentaciones se abordaron respectivamente los subtemas restantes (“¿Cómo era la vida en sus ciudades?” y “CCómo se expresaba la imposición de ese poder en el arte?”).

En cada una de las presentaciones, los grupos de estudiantes realizaron una explicación propia de porqué seleccionaron ese subtema y no otro. Desplegaron explicaciones leyendo los textos breves que acompañaban las imágenes presentadas pero ampliando ideas a partir de la observación de esas imágenes (sobre todo 
de lo que ellos veían en esas imágenes), y cuál es la relación que encontraban de ese subtema con el modo de gobernar de los faraones. Todas y cada una de esas ampliaciones fueron orientadas por la intervención en forma de preguntas por parte de los docentes e investigadores y de sus propios/as compañeros/as. Por lo que cada exposición se desplegó de manera coloquial en cada caso.

Luego de concluido el desarrollo de la propuesta en sus sucesivas clases, las valoraciones realizadas sobre la experiencia emprendida tanto por el profesor como por sus estudiantes destacaron:

Cuadro 2

\begin{tabular}{|l|l|}
\hline \multicolumn{2}{|c|}{ Propuesta de Enseñanza 1 } \\
\hline \multicolumn{1}{|c|}{$\begin{array}{c}\text { Aspectos destacados } \\
\text { reconocidos por el profesorado }\end{array}$} & \multicolumn{1}{c|}{$\begin{array}{c}\text { Logros reconocidos por } \\
\text { los/las estudiantes }\end{array}$} \\
\hline $\begin{array}{l}\text { Que las imágenes les ayudaron a } \\
\text { explicar el tema }\end{array}$ & $\begin{array}{l}\text { "leer las imágenes sobre como gobernaban los } \\
\text { faraones y cómo vivía la gente" } \\
\text { "los faraones gobernaban de diferentes formas, les } \\
\text { hacían creer a la gente en ellos, para hacerlos } \\
\text { trabajar mucho. Para hacer las obras que ellos } \\
\text { querían. Los lugares donde vivían y cómo querían } \\
\text { que viviera la gente". }\end{array}$ \\
\hline $\begin{array}{l}\text { Que aprendieron a utilizar y } \\
\text { armar una presentación en } \\
\text { formato PowerPoint }\end{array}$ & $\begin{array}{l}\text { "no sabíamos usar ese programa, nos gustó } \\
\text { aprender a utilizar sus efectos" }\end{array}$ \\
\hline $\begin{array}{l}\text { Que el PowerPoint les permitió } \\
\text { comprender el tema de otra } \\
\text { manera }\end{array}$ & $\begin{array}{l}\text { "porque vas armando lo que tenés que decir, y lo } \\
\text { haces vos" }\end{array}$ \\
\hline $\begin{array}{l}\text { Que debieron realizar una } \\
\text { selección de imágenes en } \\
\text { relación al subtema } \\
\text { tesestimando otras posibles) }\end{array}$ & $\begin{array}{l}\text { "y que es difícil realizarla solos porque hay mucha } \\
\text { información en internet" }\end{array}$ \\
\hline $\begin{array}{l}\text { escribir vos, y tampoco podés poner mucha } \\
\text { información sino la más importante..." }\end{array}$ \\
\hline
\end{tabular}

Fuente: elaboración propia. 
En el caso de la propuesta 2, el tema a enseñar fue la Conquista de América, haciendo hincapié en el choque cultural. Después de analizar las razones del domino español sobre los indígenas, se abordó el impacto que los europeos experimentaron en el contacto con la realidad americana y los cambios experimentados tras la llegada de los españoles. El análisis del choque cultural implicó que pensaran en una situación compleja, es decir, en el encuentro con la otredad. En este contexto, se desarrollaron tres clases a través de las cuales los contenidos fueron abordados recurriendo a un dispositivo digital: el audiocuento en formato PPT (PowerPoint).

En la primera clase se trabajó retomando las ideas sobre las causas del dominio español. En función de esas causas, se llevó a cabo una contextualización histórica de la Conquista de América a partir de la utilización de un PowerPoint que incluyó imágenes, mapas y una red conceptual sobre las etapas de la conquista. Durante éste primer momento, se hizo hincapié en el análisis de una imagen a partir de la cual observar la mirada del otro en términos de choque cultural. Luego de la misma se presentó y proyectó la versión digital del cuento "El descubrimiento" de Eduardo Galeano. Tras la presentación se planteó una instancia de debate y reflexión sobre las sensaciones generadas por el video y se bosquejó una serie de preguntas para trabajar, primero en forma oral y luego de manera escrita. Dichas preguntas bucearon sobre:

- ¿Cómo describe el "encuentro con el otro"?

- ¿Qué descubrieron el 12 de Octubre los pueblos indígenas?

- ¿Quiénes piensan esto? ¿Por qué?

En la segunda clase, se recuperaron las ideas surgidas del primer encuentro y se avanzó sobre la comprensión del proceso histórico a partir de los conceptos claves de conquista y colonización. Asimismo, se presentó y visualizó el audiocuento "Los sueños del viejo Antonio" en formato PowerPoint. Al respecto, los/las estudiantes visualizaron con mucha atención el audiocuento y luego se plantearon algunas preguntas para reflexionar en conjunto en el pizarrón: ¿Qué sueñan los personajes del cuento? ¿A quiénes 
representan esos sueños? ¿Por qué le preocupa al rey su sueño? ¿Qué relación encuentran con el relato de la clase anterior?

Los/las estudiantes no sólo reflexionaron en conjunto sino que también escribieron una serie de relatos en función de las preguntas y de las opiniones surgidas del conjunto de la clase. Por último, se les planteó una instancia de escritura de un relato grupal (de a dos o tres personas) sobre el choque cultural en América. Relato sobre el que debieron elaborar un audiocuento utilizando el formato de PowerPoint para el próximo encuentro.

Finalmente, en la última y tercera clase presentaron los audiocuentos elaborados en grupos sobre el impacto de la Conquista de América y el choque cultural. En cada elaboración tuvieron en cuenta las instancias de debate y escritura de las clases anteriores. En total se presentaron diez trabajos, de los cuales nueve de las presentaciones fueron elaborados en formato de PowerPoint y uno mediante el programa Kine Master. En cada trabajo los/las estudiantes incluyeron imágenes, audio propio con el relato del cuento, canciones de fondo para la presentación, y en algunos casos la voz de sus padres en el relato de los audiocuentos.

En todas las presentaciones se hizo hincapié en el trauma que significó la presencia del español en América. Sin embargo, no todos/as lo narraron de manera similar. Algunos usaron el formato de cuento, otros relataron el proceso, y algunos sólo quedaron con una mirada anecdótica de los hechos, pero en relación a sus puntos de interés personales. Por otro lado, al describir el proceso algunos profundizaron en las razones del dominio español sobre los indígenas (aprovechamiento de las creencias, superioridad en el armamento). Otros mencionaron el sometimiento sufrido por los indígenas, por ejemplo con la pérdida de libertad. Y, por último, algunos dieron cuenta de la complejidad del encuentro entre dos culturas que no logran entenderse.

En la instancia final y posterior al desarrollo de estos encuentros, tanto el profesor como sus estudiantes destacaron lo siguiente: 
Cuadro 3

\begin{tabular}{|c|c|}
\hline \multicolumn{2}{|c|}{ Propuesta de Enseñanza 2} \\
\hline $\begin{array}{l}\text { Aspectos destacados reconocidos } \\
\text { por el profesorado }\end{array}$ & $\begin{array}{l}\text { Logros reconocidos por } \\
\text { los/las estudiantes }\end{array}$ \\
\hline $\begin{array}{l}\text { Que - a partir del trabajo con } \\
\text { imágenes y audio - lograron } \\
\text { reconstruir el proceso histórico } \\
\text { estudiado. }\end{array}$ & $\begin{array}{l}\text { “Todos los hicimos con los mismos elementos, } \\
\text { pero los interpretamos de diferentes } \\
\text { maneras." "En teoría, no lo creamos, sino que } \\
\text { lo recreamos. En función de las diferentes } \\
\text { miradas pudimos reconstruir el choque } \\
\text { cultural. Pudimos recrear el momento." } \\
\text { "Sobre como fue el encuentro con los } \\
\text { españoles con respecto a los indígenas. } \\
\text { Entender que la conquista fue un encuentro } \\
\text { donde no hubo mucha aceptación entre sí." }\end{array}$ \\
\hline $\begin{array}{l}\text { Que la utilización del audiocuento } \\
\text { les permitió comprender el proceso } \\
\text { histórico sin tener que recurrir a } \\
\text { lectura extra }\end{array}$ & $\begin{array}{l}\text { "nosotros lo hicimos con los mismos } \\
\text { conocimientos, todos los materiales que } \\
\text { teníamos hasta el momento. A partir de los } \\
\text { hechos pudimos reconstruir un nuevo relato } \\
\text { teniendo en cuenta los relatos elaborados." }\end{array}$ \\
\hline $\begin{array}{l}\text { Que el manejo de la tecnología a } \\
\text { diferencia del libro de texto generó } \\
\text { un mayor interés por la temática } \\
\text { estudiada }\end{array}$ & $\begin{array}{l}\text { "Porque utilizamos la tecnología, fue más } \\
\text { interesante", "Si, porque nos atrae más la } \\
\text { atención que los libros", “Aburrido era agarrar } \\
\text { el cuadernillo y leer", "Lo bueno de ésta } \\
\text { actividad es cada uno dio su opinión y lo que } \\
\text { pensaba sobre el choque cultural y no repetía } \\
\text { lo que decía el libro." }\end{array}$ \\
\hline $\begin{array}{l}\text { Que les resulta más fácil la } \\
\text { construcción de PowerPoint a } \\
\text { diferencia de otros trabajos escritos, } \\
\text { aunque destacan que les resulta } \\
\text { complicada la selección de imágenes: }\end{array}$ & $\begin{array}{l}\text { "El cuento no nos costó porque ya veníamos } \\
\text { desde hace mucho con el tema, pero lo que } \\
\text { nos costó fue el Power para poder resumirlo } \\
\text { todo y que quede", "Nos costó saber que } \\
\text { imágenes utilizar y desde que mirada abordar } \\
\text { el proceso." }\end{array}$ \\
\hline
\end{tabular}




\section{...AL APRENDIZAJE DE LA HISTORIA EN LA CULTURA DIGITAL}

Enseñar para que se aprenda historia construyendo sentido histórico fue un eje central y transversal en ambas experiencias. Y en cada trayecto desarrollado, fuimos en búsqueda de reajustes y - sobre todo - de lo que era novedoso en el desarrollo de la construcción metodológica (Edelstein, 1996) emprendida en las clases de historia de ambos casos.

El dispositivo digital construido conjuntamente fue el PowerPoint. ¿Residió en ello lo novedad? Indudablemente que no, de otro modo estaríamos yendo por encima de nuestros iniciales presupuestos. En uno y otro caso, el PowerPoint fue utilizado para la realización de presentaciones audiovisuales, y en el caso de la propuesta 2 incorporando el audiocuento. Es sabido que el PPT representa un dispositivo multidigital que permite enseñar a partir de una "diversidad de recursos y soportes digitales (imágenes, textos, música, documentos de época, relatos, gráficos y mapas, entre otros)” (Jara; Salto, 2015). Pero las experiencias emprendidas demostraron además su alcance en el aprendizaje, ubicando a los/las estudiantes en un rol más activo, movilizante y participativo en relación con otros modos de saber y aprender historia escolar. Por lo tanto, si la utilización del PowerPoint fue importante, el alcance que provocó para el aprendizaje de la historia representó la novedad.

De alguna manera, la incorporación de la cultura digital favoreció la construcción de conciencia histórica en dos direcciones ${ }^{6}$. Por un lado, en la construcción de una conciencia histórica crítica (es decir, las mediaciones digitales permitieron la formulación de puntos de vistas históricos frente a posiciones más clásicas sobre los contenidos vistos). Por otro lado, en la construcción de una conciencia histórica genética (en la medida en que se alentaron diferentes puntos de vistas que pudieron aceptarse a partir del reconocimiento del cambio temporal en relación al presente). En ambas direcciones, el trabajo de elaboración dado en el aprendizaje del estudiantado en cuestión implicó instancias de argumentaciones fundadas en la multicausalidad y multiperspectividad al calor de los contenidos observados. En este sentido, las producciones audiovisuales realizadas nos resultaron potentes medios de expresión y construcción narrativa en relación a la formación de ese pensamiento y conciencia histórica. A partir de la incorporación de su cultura digital y del uso de los dispositivos mencionados, pudieron asumir un activo papel en la (re)construcción de los 
procesos observados. Orientaciones que permitieron una elaboración distinta a los modos tradicionales y ejemplares que según Rüsen (1992) se hayan bastante extendidos en nuestras prácticas de enseñanzas y de aprendizajes de la historia.

En esta dirección, es relevante destacar que la utilización del PowerPoint y el enseñar a manipular las herramientas de su formato no obedeció a criterios tecnicistas o instrumentales. Quizás sea más pertinente formular un interrogante más y en otros términos: ¿reflejo el PowerPoint una mediación constructiva alternativa de los/las estudiantes para el conocimiento histórico escolar? A partir de la experiencia compartida consideramos que sí. No porque el PowerPoint haya contenido herramientas facilitadoras del aprendizaje en sí mismas. Sino porque la manipulación que hicieron los/las estudiantes sobre esos dispositivos los organizaron a partir de problemas e intencionalidades articulados a los contenidos planteados.

En este sentido, y en el marco de ambas propuestas, consideramos que se generaron otras posibilidades para la concreción de las intencionalidades propuestas. Intencionalidades que, en uno y otro caso, se propusieron contribuir a la formación de un pensamiento histórico que permitiera comprender situaciones y experiencias históricas del pasado en relación a la percepción, las interpretaciones y orientaciones que el estudiantado pudiera construir desde su presente. Es decir, comprensiones pensadas y analizadas desde sus sentidos del presente y de sus propias experiencias cotidianas. Orientaciones que se vieron favorecidas por la mediación intencional de su cultura digital en relación a unos contenidos históricos dotando de sentido al pasado en función de su presente. Orientación temporal en la que asumieron formas narrativas que les permitieron caracterizar, definir y posicionarse frente a cada situación y experiencia histórica presentada. Ellos/as no debieron entonces transformarse en expertos de las tecnologías, sino que debieron manipularlas de tal manera que les permitieran realizar una construcción distinta a partir de sus propios operadores de aprendizaje (hipotetizar, interpretar, analizar, diseñar, comprender, entre otros). Así, las imágenes y audiovisuales permitieron estimular diferentes percepciones y argumentaciones propias a partir de lo observado. $\mathrm{Y}$, asimismo, interactuar/compartir esas habilidades en producciones digitales concretas. Por lo que múltiples representaciones se hicieron posibles en dichas producciones (tal como lo presentamos en el cuadro 2 y 3 ). Y en ello 
profesorado acompaño activamente este proceso de construcción en el aprendizaje de la historia de sus estudiantes.

Fuimos participes de dos experiencias en las que nos quedó claro que los dispositivos digitales (PowerPoint y audiocuentos en formato PowerPoint) fueron una opción viable y potente. Que estos dispositivos generaron un involucramiento mayor con las temáticas abordadas. Que sin la predisposición e involucramiento activo del estudiantado es difícil concretar propuestas de enseñanza que permitan la generación de pensamiento histórico y consciencia histórica. Pero que esos potenciales también podrían no haberse dado. Y que sin finalidades claras y un recorte temático acotado, las potencialidades de un dispositivo digital se diluyen solo en la mera prescripción de la enseñanza de la historia y se ven obturadas en su práctica concreta.

Finalmente, ¿que quedó de los presupuestos iniciales de los que partimos como orientadores en la construcción de dispositivos digitales para la enseñanza y el aprendizaje de la historia? Ambas experiencias demostraron la influencia de la cultura digital tanto en la enseñanza como en el aprendizaje de la historia. Y que en cada caso, no solo el profesorado se vio interpelado en la construcción de un dispositivo en cuestión sino también el propio estudiantado. Unos y otros fueron participes de situaciones didácticas en las que se favorecieron otros modos de comprensión histórica y algunos cambios en las formas de enseñar historia desde otras mediaciones.

En este sentido, la tercera clase de cada secuencia didáctica trabajada demostró que fue posible ir más allá del uso instrumental de la tecnología. En cada caso, ésta se transformó en un soporte, y no en un fin en sí mismo, para el intercambio cultural y de comunicación sobre temas históricos.

La apuesta residió en incorporar efectivamente algunos dispositivos digitales que -en relación a la disciplina escolar historia- puedan favorecer el aprendizaje autónomo, crítico y constructivo en estudiantes de nivel medio. Y con ello, generar - tal como se evidencia en los comentarios del propio estudiantado - un cuestionamiento del monopolio de la cultura letrada en la clase escolar, asumiendo la cultura digital como un habitus presente en las relaciones pedagógicas cotidianas y en las estrategias de aprendizaje de los/las estudiantes de nivel medio.

Ello demando reconocer las exigencias de una comunicación múltiple al momento de enseñar historia en contextos de cultura digital y admitir que la 
construcción de conocimientos ya no es unidireccional. Sino que se debe aspirar a convivir con las tensiones epistemológicas que nos provocan los habitus digitales en nuestras clases de historia.

El profesorado continúa teniendo un rol fundamental, tanto en las finalidades (el para qué usarlos en la enseñanza de un contenido histórico) como en la organización que puede establecer en el desarrollo de sus secuencias didácticas. Pero también en la necesidad de que el estudiantado vincule el uso de esos dispositivos con los conocimientos históricos en el marco de su propia cultura digital para la formación de su conciencia histórica.

Desde nuestro punto de vista, no se trata entonces de abrigar expectativas desmesuradas sobre su uso. Sino de identificar las limitaciones sobre las cuales trabajar e identificar el potencial que tiene la cultura digital para "la construcción de nuevas racionalidades vinculadas al conocimiento histórico escolar, a las finalidades y a los modos de construir metodológicamente en el aula de la escuela secundaria" (Jara; Salto, 2015, p.58).

\section{...PARA SEGUIR PENSANDO EN APRENDIZAJES}

Llegados a este punto en el proceso investigativo es interesante pensar en algunas coordenadas que nos habiliten nuevas preguntas comprensivas para saber más acerca del aprendizaje escolar mediado por tecnologías. Sostenemos que el aprendizaje escolar en general y el aprendizaje escolar de las ciencias sociales y de la historia es un área de vacancia. Muchas veces porque sólo se esgrimen presupuestos generales, y en algunos casos anacrónicos, que no prestan demasiada atención a la diversidad de contextos en los que debe abordarse cualquier discusión sobre esta temática. Estamos en condiciones de sostener que se sabe poco de cómo aprenden los estudiantes en el aula de historia y se sabe menos sobre cómo es ese aprendizaje mediado por un contexto tecnológico.

Estamos interesados en conocer las particularidades del aprendizaje de la historia basado en la comprensión de la construcción de la explicación histórica, de las interrelaciones entre sujetos, acontecimientos y espacios históricos para dar cuenta de los cambios sociales, de la temporalidad, de las fuentes. Buscamos la argumentación abierta al debate democrático, que se plantea preguntas y que pretende provocar nuevas preguntas (Santisteban, 2010). 
Nos interesa el aprendizaje que circula en las aulas de historia de la escuela media. Es decir, el aprendizaje que realizan las/los adolescentes, quienes accionan los objetos digitales para usos que oscilan en una escala que va de muy imaginativos y creativos a una acción de repetición inconsciente.

Los estudios sobre los usos de la tecnología en el campo educativo (Gardner; Davies, 2014) dan cuenta que los medios digitales ofrecen oportunidades de lanzar y modelar productos propios. Que permiten publicar, tomar notas, crear y reflexionar; esto es, ser creador del propio conocimiento y su conciencia histórica. Y que también pueden potenciar la capacidad de utilizar formas diversas de comprensión, conocimiento, expresión y crítica, es decir, impulsar sus inteligencias múltiples.

A partir de estas coordenadas: pensamos además desde una perspectiva del conocimiento histórico signado por la complejidad; desde el presupuesto de una generación de adolescentes aprendices en la que los medios de comunicación dominantes modelan sus costumbres cognitivas, conductuales, de presentación de uno mismo y de relación con los demás. Pero ante la cual pueden plantear sus propias reelaboraciones, lo que piensan, dicen, hacen y sueñan. En este sentido es que el presente contexto digital continúa interpelando e interesando en:

- Detectar para analizar las acciones cognitivas estudiantiles cuando reconocen diversas relaciones causales, elaboran inferencias, imaginan situaciones y las argumentan

- Indagar las disímiles explicaciones del proceso o acontecimiento estudiado en soportes tecnológicos

- Registrar durante el proceso de abordaje de los diversos usos de las tecnologías si se van construyendo conceptualizaciones sobre el mundo social a partir de analogías, comparaciones, diferenciaciones.

- Bucear en las representaciones sociales de los estudiantes y analizar si se fundamentan en estereotipos construidos muchas veces en la historia escolar.

- Analizar si se involucran en las acciones que realizan y si imaginan y contextualizan la situación histórica y dan cuenta del proceso de construcción conceptual propia de la disciplina histórica, tales como las 
relaciones de los tiempos en el "mundo histórico" y en las diversas textualidades que ofrece lo digital.

\section{REFERENCIAS}

BUCKINGHAM, David. Más allá de la tecnología: aprendizaje infantil en la era de la cultura digital. Buenos Aires: Manantial, 2008.

DUSSEL, Inés. La escuela y los nuevos medios digitales. Notas para pensar las relaciones con el saber en la era digital. In: AA.VV. La Educación Alterada: aproximaciones a la escuela del siglo XXI. Córdoba: Universidad Nacional de Villa María (Eduvim); Salidas al mar ediciones, 2010.

EDELSTEIN, Gloria. Un capítulo pendiente: el método en el debate didáctico contemporáneo. In: AA.VV. Corrientes didácticas contemporáneas. Buenos Aires: Paidós, 1996. p.75-89.

GARDNER, Howard; DAVIES, Katie. La generación APP: cómo los jóvenes gestionan su identidad, su privacidad y su imaginación en el mundo digital. Buenos Aires: Paidós, 2014.

JARA, Miguel A.; SALTO, Víctor. Los dispositivos multidigitales en las clases de historia. Novedades Educativas, Buenos aires: Centro de publicaciones educativas y material didáctico S.R.L., Sept., año 27, n.297, Sept. 2015.

PAGÈS, Joan; SANTISTEBAN, Antoni. Cambios y continuidades: aprender la temporalidad histórica. In: JARA, Miguel A. (Comp.) Enseñanza de la historia: debates y propuestas. Neuquén: Educo, 2008. p.91-27.

RÜSEN, Jörn. El desarrollo de la competencia narrativa en el aprendizaje histórico. Una hipótesis ontogenética relativa a la conciencia moral. Trad. Silvia Finocchio. Propuesta Educativa, Argentina: Flacso, n.7, p.27-37, 1992.

. A razão histórica: teoria da história: os fundamentos da consciência histórica. Trad. Estevão de Rezende Martins. Brasília: Ed. UnB, 2001.

SANTISTEBAN, Antoni. La formación en competencias del pensamiento histórico. Clío \& Asociados: la historia enseñada, La Plata: Universidad Nacional del Litoral, n.14, 2010.

SALTO, Víctor. Modos, límites y posibilidades de la cultura digital reconocidos por el profesorado en historia en sus experiencias de enseñanza. In: JORNADAS INTERESCUELAS/DEPARTAMENTOS DE HISTORIA, 15. Comodoro Rivadavia Chubut: Universidad Nacional de la Patagonia San Juan Bosco. Facultad de Humanidades y Ciencias Sociales, 2015. 


\section{NOTAS}

${ }^{1}$ Ver algunos de estos resultados generales en el artículo de Jara y Tirachini en el presente dossier.

${ }^{2}$ Algunos avances sobre los resultados de estas entrevistas y el análisis de los mismos pueden consultarse en Salto (2015).

${ }^{3}$ En nuestra región, los establecimientos educativos son organizados presupuestariamente en tres categorías distintas en función de la cantidad de estudiantes con la que cuentan. Las escuelas con mayor número de estudiantes (superiores a 500 estudiantes son considerados de primera categoría; con menos de 500 estudiantes, pero con más de 150 se consideran de segunda categoría; y las escuelas con menos de 150 estudiantes de tercera categoría). La distinción de las escuelas por categoría no solo es indicativa de la población que asiste ni de la mayor o inferior superpoblación de ellas, sino de la diferencia de presupuesto que se le asigna en función de su categoría. Las escuelas que cuenten con mayor asistencia de estudiantes reciben una partida presupuestaria mayor por ciclo lectivo. Y, por lo tanto, contar o disponer con mayor dotación de infraestructura y equipamiento didáctico. Otro aspecto a tener en cuenta es que, al menos en las escuelas de Neuquén y Río Negro, los establecimientos educativos diurnos cuentan con planes de estudio que organizan el cursado en el nivel en 5 años de duración. Por lo que cada escuela divide el cursado de estos 5 años en dos ciclos: ciclo básico $\left(1^{\circ}, 2^{\circ}\right.$ y $3^{\circ}$ año $)$ y ciclo superior $\left(4^{\circ}\right.$ y $\left.5^{\circ}\right)$. Los planes de estudio que pueden organizar la formación escolar ofrecida por cada escuela pueden ser varios. Planes que comparten una formación escolar común para el ciclo básico, pero con orientaciones diferentes para el ciclo superior. En función del plan y de las orientaciones ofrecidas por cada plan, la asignatura historia en algunas escuelas puede ser dictada en los 5 años del secundario mientras que en otras solo puede dictarse para el ciclo básico o solo en algunos casos en el ciclo superior en relación a asignaturas afines a la historia y las ciencias sociales. En términos generales, las escuelas de nivel medio con orientación técnica ofrecen formación en historia solo en su ciclo básico. Mientras que en las escuelas medias comunes la orientación ofrecida, según el plan, pueden incluir la formación en historia y ciencias sociales hasta el $5^{\circ}$ año. Así, la formación escolar ofrecida, en relación a la historia, es heterogénea y se haya condicionada a la existencia de una serie de planes diferentes con innumerables listas de orientaciones existentes en cada jurisdicción. En el caso de Neuquén (según el último relevamiento realizado en el 2013 por el departamento de Estadística de la Dirección de Planeamiento Educativo dependiente del Consejo Provincial de Educación), en el nivel medio se cuenta actualmente con 122 establecimientos educativos que ofrecen 8 orientaciones con 64 titulaciones diferentes para sus estudiantes. Las experiencias de enseñanza y aprendizaje que presentamos en este artículo fueron realizadas en dos establecimientos de esta última jurisdicción educativa.

${ }^{4}$ Recuperamos a partir de estos aspectos, los aportes de algunas líneas de investigación que orientaron ambas experiencias en el marco del proyecto emprendido y que en los últimos años han venido promoviendo la enseñanza en relación al aprendizaje para la formación del pensamiento y la conciencia histórica. Entendemos que varias de ellas han sido estimu- 
ladas, entre otras posibles, a partir de las consideraciones de Jörn Rüsen $(1992 ; 2001)$ sobre la conciencia histórica y de Pagès y Santisteban $(2008 ; 2010)$ sobre la formación del pensamiento histórico. En esta línea, el trabajo colaborativo con los profesores implicados partió de considerar que la enseñanza de la temporalidad histórica contribuye a dicha formación y ofrece la posibilidad de dotar de nuevos sentidos a la conciencia histórica de las nuevas generaciones. Recuperamos entonces dos ideas rectoras para observar la influencia y el favorecimiento de una formación de la conciencia histórica a partir de la incorporación de la cultura digital en la enseñanza de la historia. Por un lado, la idea de aportar a la creación de sentido histórico entendiendo que la conciencia histórica se refiere a "la suma de las operaciones mentales con las cuales los hombres interpretan la experiencia de evolución temporal de su mundo y de sí mismos, de modo que puedan orientar, intencionalmente, su vida práctica en el tiempo" (Rüsen, 2001, p.57). Por otro, la idea de que la escuela y la historia escolar pueden aportar, a partir de determinadas mediaciones didácticas, en la construcción de esa conciencia en las jóvenes generaciones. Conciencia que es preexistente al aprendizaje escolar de la historia. Pero que -a partir de ese aprendizaje- permite resignificar (en términos de nuevas relaciones temporales con las experiencias del pasado) y orientar la comprensión del presente y alentar expectativas futuras. Es decir, permiten adquirir habilidades, que en términos de Rüsen, son narrativas, interpretativas y de orientación - que no siempre se pueden aprender en otros ámbitos - para pensar experiencias pasadas en relación a su vida cotidiana, su realidad, cultura y vida humana. En función de estas ideas rectoras, nos propusimos avanzar en nuestra indagación para observar las contribuciones de la incorporación de la cultura digital para la formación del pensamiento y la conciencia histórica en jóvenes de nivel medio en escuelas de la norpatagonia argentina.

${ }^{5}$ Ambos establecimientos ubicados en la ciudad de Neuquén capital, provincia del mismo nombre, en la norpatagonia argentina.

${ }^{6}$ Rüsen (1992) destaca cuatro tipos de ejercicio de conciencia histórica: la tradicional (en la que el pasado se ofrece como un todo, como continuidad de los modos de vida y de la cultura del pasado), la ejemplar (en la que las experiencias del pasado se representan como reglas generales del cambio temporal y de la conducta humana), la crítica (en la que se permite la formulación de preguntas y puntos de vistas que permiten posicionarse y negar otros) y la genética (en el que se promueve una perspectiva más amplia del cambio temporal que apunta a captar la complejidad de la vida social). Las dos primeras promueven una actitud pasiva del estudiantado en relación a la construcción del conocimiento histórico; mientras que las dos segundas se orientan a permitir una participación activa de los mismos en el proceso de enseñanza y de aprendizaje de la historia.

Artigo recebido em 8 de abril de 2016. Aprovado em 6 de junho de 2016. 